\title{
THE PROBLEM OF A 'LOGIC OF THE EMO- TIONS' AND AFFECTIVE MEMORY. II.
}

\author{
BY PROFESSOR WILBUR M. URBAN, \\ Ursmus College.
}

The second portion of our discussion concerns itself with the problem of affective memory, the existence of which had to be assumed at various points in the preceding portion of this paper. Affective memory is the presupposition of the doctrine of emotional abstracts, as indeed of any theory of emotional continuity and evolution. It is unnecessary to point out that this has been assumed in all the English psychology which underlies hedonistic ethics and indeed affective memory in its one untenable form. It is this very assumption of a hedonic memory which makes the conception of hedonic calculus untenable. Yet, as M. Pillon has brought to our notice, both Spencer and Bain assumed the existence of a memory of emotions without going into careful analysis.' It is the modern ' doctrine of

${ }^{1}$ Revue Phalosophique, Feb., IgoI. In addition to showing historically the extent to which affective memory is presupposed by the earlier descriptive psychologists in their reconstruction of the mental life, Pillon reconsiders the grounds for the doctrine. He points out that the distinctions between real and ideal emotions (James), abstract-false and concrete-true emotional memory (Ribot), are distinctions of degree, not of kind. What distinguishes the memory of a concrete particular from an abstract, ideal emotion is merely the tendency of the former to localization in time, through ideal associations. The re currence of particular emotions without ideal links is explained by immediate association. While the tendency of abstract emotions is always to pass over into particular through concretion or simultaneous association of ideal content -and not until then are they refelt (ressenti)-they may however be recognized (reconnu) without particular ideal content. This distinction between the mere recognition of a re-presented emotion and the feeling again of a particular, is indeed important, and the peculiar warmth of the latter seems to presuppose ideas as their condition.

In answer to the criticism that the so-called remembered emotions are really new, Pillon quotes from a passage in the 'Nouvelle Héloise' (Part IV. Letter $X$ VII.) where Saint-Preux describes himself as reviving, in the presence of the 
elements' which develops a priori arguments against affective memory.

That doctrine of elements, in finding the constant element of all affective states in the two abstract qualities, pleasure and pain, as ultimate reactions of the organism upon presented content of consciousness, has been unable to conceive these as in turn presented and subject to the laws of presentation, memory, association and generalization. Of course, logically, the same a priori arguments which oppose themselves to affective memory would be equally strong against the notion that ideas may be associated through the mediation of an affective state common to both. Can an emotional state be presented and represented to consciousness-that is the problem. It need not be pointed out here that the æsthetic theories of Scheingefühle and Einfuhlung assume this. Let us first recall briefly the phenomena of ideal memory and recognition and compare them with the alleged phenomena of affective memory. In the first place, then, there is a voluntary recall of sensational images and corresponding to it there is a so-called voluntary recall of emotional states as such, characteristic of what Ribot calls the affective type. The peculiarity of this phenomenon is that, while use is made of ideal associations or of organic attitude to bring up an emotional state, the object of the voluntary recall is a past emotion which is recognized as such when tt comes." This ability of voluntary recall of emotions may quite conceivably be

old scenes of love, the same emotions, but upon recognizing their futility he falls into rage and despair. He considers this passage a distınct proof of a recognized difference in the mind of Rousscau between the revived emotion, which appears according to the laws of association, and the new and full reaction of which they are the presupposition.

'Among others M. Sully-Prudbomme discloses that in his literary activity he does not seek primarily to objectify memories of sensations and ideas, but rather to reinstate a certain emotion, sentiment or mood, careless of the prerious ideal elements if the emotional attitude be retained. The fact of 1 mportance here is that the objective value which is to be the center of the work of art is the emotional attitude which becomes both the center of unity for the work itself and a test of the reality of the result. In his 'Imagination créatrace' Ribot finds certain forms of art where the dominating unity is an 'émo. tion fixe' and more subtle forms of creation where the chief element of unity is an emotional abstract, a mood or sentiment, which acts as a universal, gathering under it, by way of subalternation, particular feelings and emotions. 
limited, and memory, in the sense of recognition, still remain, just as we find memory of sensations in those who can recognize, for instance, various shades of red perfectly but cannot voluntarily recall them.

In the second place, parallel with the spontaneous appearance of images in consciousness there are well-authenticated cases of a spontaneous appearance in consciousness of particular emotional states which are recognized as familiar before the appearance in consciousness of the ideal content which shall definitely locate them in time. In this connection may be mentioned the classical case of $M$. Littre given by Ribot and a case given by Mauxion in a recent article in the Revue Philosophique, ${ }^{1}$ and I shall add to the group one from my personal experience. A few years ago, while living abroad, there came into my consciousness entirely without associational conditions that were recognizable a peculiar emotional tone which I recognized as having been experienced before with peculiar intensity. I located it finally as the emotional overtone of a peculiarly desolate bit of anthracite coal region. So strong and marked was it that it developed into particular emotions of great vividness and sufficient to lead immediately to a bit of descriptive writing. The point of psychological interest is that

'In a second article in the February number of the Revue, entitled, ' La vraie mémoire affective,' the writer, M. Mauxion, is disposed to class all enotions which are connected with revived images as new, and to explain the judgment of such men as Sully-Prudhomme and Saint-Preux (as described above) as an illusion of auto-sympathy. The true emotional memory consists, he hints, in the recurrence of an emotional state independent of ideal content, for which he gives illustrations similar to the spontaneous recurrence of emotions described above. These recurrences he thinks of as conditioned wholly by the vital feeling or dominant mood. This true affective nemory is thus wholly motor, like the motor memory of speech. Motor tendencies become organized into fundamental somatic resonances, or systems, whose recall the faintest suggestion can mediate. The author calls attention to the tendency of certain natural phenomena to develop definite organized rhythms in the beholder, which become emotional concomitants. Such, for instance, are the moods of the sea, the rising and setting of the sun. He also notes the dependence of emotional result upon the dominant organic resonance-the mood or vital feeling-tive phenomena to which in my earlier paper was given the name of subsumption. True as this concept of the motor basis of emotional memory is, the writer does not seem to recognize the possibility of abstracting the systems of relations from the organic content itself. 
with the closest search no ideal content could be found which would account for its revival. It is probably explained by the fact that a somewhat similar feeling had that day been generated by wholly different content-the squalor of a certain quarter in a foreign city, and that there had been direct emotional recall through emotion.

In the third place, we find simple recognition of new emotions or moods in life or in art as like some old experience or at least as familiar. Although the facts in favor of cases of direct recall seem sufficient, however its mechanism be explained, it is rather upon the phenomenon of recognition of affective states, as such, that the continuity of affective life through generalization of the emotions is based. It would seem that this point has not been sufficiently understood in the current discussions of this problem. For it is upon recognition rather than direct recall that the continuity of the ideal content of consciousness rests, and the case should not be made any more difficult for affective continuity.

An analysis of the methods which underlie experimentation upon sensational memory discloses the fact that it is with phenomena of recognition that we are really concerned. In the methods of identification and reproduction as applied, for instance, to experimentation upon the memory for sound and muscular movement it is really the accuracy of recognition that is measured. Of course it is possible to voluntarily reproduce sensations without the stimulus for recognition, but as in the case of Külpe's subject who could not recall color tones, 'the process of recognition remains perfectly normal,' that is, it is possible to carry out the memory experiments by the method of identification without the least trace of voluntary recall. In fact, in my own laboratory work I found a subject without the so-called auditory memory, whose memory curve for tones was perfectly normal. Likewise in the recognition of reproduced arm movements I cannot find any moment of comparison between a memory image and the arm movement reproduced. The point is that in much of memory experimentation there is no conscious comparison of images but only recognition of the new sensations as same or different or by means of verbal association. As 
Kulpe says, in his searching critique of the traditional doctrine of memory and association, "we are ordinarily unable to institute a direct comparison of memorial image with perception; * * conditions are unfavorable to comparison." If then, after Külpe's critique, memory reduces itself largely to recognition, and this to the liability of reproduction by peripherally stimulated sensations of the organic element making up the mood of recognition, the whole problem of affective memory becomes this: Can an affective state become the presupposition of another affective state, that is, the mood of recognition? Is feeling, emotion, capable of becoming a presupposition of a judgment feeling of familiarity? This is, of course, a question for empirical research, and recent investigators, Meinong, Ehrenfels, Schwartz, Witasek, have pronounced themselves affirmatively on the question. ${ }^{1}$ To take one crucial case: when Professor James tells us that we may produce an emotion by putting ourselves in the appropriate bodily attitude and when we set out to do so and find it to be true, certainly we have meant to reproduce that emotion, whatever it is theoretically, and we recognize it as the true one when it comes. ${ }^{2}$ It is then the function of assimilation in recognition which underlies the formation of generalized emotions just as it underlies the formation of general ideas.

As to the facts of affective recognition, it follows exactly such laws as would be expected on the assumption that the different orders of affective experience relate themselves as general and particular. It is a well-established law of revivability and recognition in the sphere of sensation and ideas that the general recurs before the particular and is recognized before

${ }^{1}$ Cf. Part I. of this article.

'In this connection I have to record a case of 'Sprachgefiuhl' which shows beautifully the way in which a remembered feeling without any ideal content may act as a criterion for a remembered word, and may mediate or prevent the recall of the word. Having, by intercourse with a particular group of people become accustomed to the more or less continuous use of the expression schablonenhaft, with all the peculiar Sprachgefuhl connected with it, I had occasion to use the English word 'conventional.' I could not remember it. The feeling, partly rhythmical, partly a suggestion of distaste, connected with schablonenhaft appeared, though $I$ could not remcmber the word. The feelning itself, however, was so distinct that when 'conventional' appeared, it was at first rcjected, siuce it did not hare the exact emotional counotation of the feeling already in consciousness. 
the particular. ' Thus, in the recall of a word that is particular, it frequently occurs that the class word appears first, and it is well known that in experimentation perception of difference precedes the perception of the direction of the difference. It is but a particular case of the general law that frequency of excitation exercises an influence upon the reproduction of an experience. In like manner, in most cases of spontaneous or volitional revivability of affective states the tendency is for the emotional abstract sentiment or mood to precede the revival of the particular emotion which depends more or less upon particular memory images. Thus in the case cited by Mauxion and in the case cited from my own experience it is the general mood which is recognized first, to be followed by the surging into consciousness of the particular emotion reactions subsumed under it. Analysis of emotional memories of places, their general mood in the sense that the term is used by Ribot, precedes the particular emotionally toned images. Again, in memory of dreams, the emotional overtone, as it has been called, may be frequently recognized on succeeding mornings as familiar, and as the same although the particular images with their emotional tone may be varied, and the general emotional tone of the dream may be recognized as familiar before any of the particulars. From my own experience it seems to be a clear case of recognition of the emotional abstract or fusion of a series of emotional experiences now fallen into obscurity. ${ }^{2}$

It is likewise true that in the presentations of art the same law holds, except that it is modified in certain ways by the technical conditions in the different arts. Thus, in some inves-

${ }^{1}$ Kulpe, 'Introduction to Psychology,' p. I74.

2I have in mind a peculiar form of dream which there is reason to believe is quite general, the dream of mounting an endless fight of steps, or a series of mountain peaks, each higher than the other-vatious forms of continued effort-a dream doubtless brought about by organic sensatious of weariuess acting as stimuli. I have had the dream at various times-until its emotional tone became quite famliar, although the actual particular content of the dream, i.c., the nature of the effort, was so vague that I could barely recall what it was, steps or mountains. And quite recently (of course it may have been an illusion) I recognized it as the dream without remernbering any of the details. 
tigations which I carried out in a class of students in the fine arts to discover wherein their sense of the reality of the work of art lay, it became clear that the criterion of reality, at least for the artistically undeveloped, is the familiarity of the emotional resonance that the work of art produces. It may be true, as Professor James insists, that the 'spurious' sentiment of the young couple before his picture of the Virgin "would have fairly made old Titian sick.' It is probable that the expression of a sentiment was not the sole end of Titian's technique. The point of psychological interest is that a sentiment was called up and it was recognized as familiar, illusion though it may have been in comparison with Titian's purpose. Careful observation of those in my classes, all of them entirely undeveloped artistically, confirmed me in the view that for the tyro the test of artistic truth is the familiarity of the total emotional resonance which the first impression awakes. The emotional unity must dominate, even to such an extent as to be almost schematic and insipid. The crude sentimentality of popular art and literature is proverbial. Except in the cases of one or two, who were notably intellectual in type, with little natural feeling for art, I found that a total sentiment or mood is recognized as familiar and true, not only temporally before representations of particular emotions, but with much more certainty. For instance, the Dancing Boys of Donatello suggested feelings of pleased familiarity which were easily traceable to memories of childish games. The response was immediate. Nevertheless, the bodily and facial emotional expressions, true as they are to nature in an artistic sense, seemed to the observers unfamiliar and almost caricature, showing clearly that the recognition of suggested organic sensations was weak. In fact, the unfamiliarity of the particular emotional expressions had a tendency to break up the first unitary emotional impression. On the other hand, the wonderful nature moods which Corot has caught rarely failed to be recognized as familiar-as having been experienced-before the details of the landscape with their particular associations and emotional tendencies were taken account of. These are merely two illustrations of what appeared to be a common occurrence.

In literature and music the same direct investigation of rec- 
ognition is not possible. The sentiment or mood, as total feeling, is rather a resultant of the entire reading or hearing, while the reality of the particular feelings may be recognized in passing. In the first reading, however, the judgment remains more or less in suspension; it is in the return after the total feeling has been caught that its particular emotions are really first fully recognized, emotionally, as part of the total feeling. It is a phenomenon of frequent occurrence that the emotional overtone of a poem may be caught in its unity, even when the energy of consciousness is so lowered that the particular images with their emotional tendencies barely enter consciousness.

Then, too, it must be remembered that in lyrical verse and music, especially if it be of a symbolic or impressionistic sort, the dominant mood is caught almost immediately and determines by its unity the recognition of the reality of the particular emotional tendencies. The 'Lotos Eaters' and the 'Raven' are good examples of this, as the first part of this article pointed out.

If sentiments and moods are generic phases of emotionalism, or definite attitudes, their liability to reproduction and recognition should be greater than that of particular emotions. Likewise, just as all schematic complexes of consciousness (general concepts, for instance) become susceptible of extension over varied stimuli, and may be reproduced by insufficient grounds, giving rise to illusions, so it is found that a schematic representation of sentiment, in general, will call it forth when the production or recognition of a particular emotion is a difficult matter.

On the ordinary theory of 'Scheingefühle,' that they result from an organic imitation of emotional expression in the work of art, recognition being based upon the definiteness of the quality of the organic sensations aroused, one should expect that the particular emotion, being more definite than the sentiment and mood, should be more easily recognized. Our experience, which was indeed the starting point of this entire discussion, is not in accord with this expectation, and we must conclude that recognition of affective states rests, not upon the definite quality of the ideal or organic elements, but rather upon the dynamic 
relation of the elements of the emotional states, and this revivability goes back ultimately to the dynamic relation to volition. But this is a question which goes over into the problem which it is proposed to discuss in the paper on the ' $æ$ sthetic attention.'

These results are, of course, not wholly in accord with the two empirical laws of emotional revival that Ribot has formulated in his 'Psychologie des sentiments.' Emotional revival, he thinks, varies directly $(a)$ with the complexity and development of the emotional state and $(b)$ with the presence of motor elements.

Revival, in the sense that it has been conceived in this papernamely, recognition of a state as familiar (whether it is new or old in any other sense has very little to do with the question), does seem to follow the first law. Sentiments, the subtler emotions, appear more susceptible to revival-both voluntary and involuntary - than particular feelings and emotions. This, as we have seen, is almost a truism in art and art criticism. Being relatively vague in particular motor content, as the result of abstraction, and such in meaning, i.e., in constant dynamic relationship to the volitional life, they are much more easily revivable and recognizable than particular emotions, which must depend for recognition upon the definiteness of particular organic and muscular sensations. If this explanation were true, it would carry the negative of Ribot's second law with it. And, in so far as I have been able to investigate my own consciousness, experience, as well as theory, seems to be against it. The more definite and particular the organic and muscular sensations, the more they are conspicuous to consciousness, the more the subject seems to be in mediis rebus, in the midst of an emotional state, and the mood of recognition of which it is the presupposition does not come to consciousness. In the case of particular emotional states we are often rightly uncertain whether it is a new or old experience. The liability to reproduction in emotional states seems rather to depend upon the extent to which they have become generic, or of constant dynamic value for volition.

The ordinary forms of speech seem to indicate this, for we say: "I am angry again"; "He has the sentiment of obligation 
strongly developed "; "I am in the same old mood again." In this matter, I can not help coming to the conclusion that Höfding's formulation of the law of affective memory is truer to the facts. "The feelings which are linked with the higher senses and ideational activity are more easily reproduced than those connected with the lower senses and organic feelings" ("Outlines,'p. 242). This formulation, to be sure, does not take account of recent discussions of the question-and uses feeling in a sense not in harmony with the present discussion, but it recognizes the same facts of introspection which have just been taken into account.

In connection with the discussion of the problem of this paper, Mr. Rutgers Marshall asked the writer what he meant by an emotion, that it could be represented to consciousness, remembered. Surely the answer to this question is not difficult, for it would be in Mr. Marshall's own terms. The breaking up of the false confusion of emotion with pleasure and pain, begun by the Lange-James theory and critically carried out by Marshall, has opened the way for the consideration of the emotion as content, as a system of organic sensations. Pleasure and pain, by their very nature, cannot be represented, but a relatively permanent group of 'instinct feelings' can, and with different algedonic coefficients at different times. All that is necessary to make conceivable theoretically what the facts of emotional memory or recognition assert empirically, is some such conception as that of the dymamic constant developed in Part I. of this paper. In the same sense that an idea is a complex of sensations, in various relations of time, space and intensity, an emotion in representation is an ideal feeling, a definite system of time and intensity relations among organic-sensation content. Representation, however, involves a degree of abstraction in which the algedonic intensity is lowered and the organic sensations dampened.' Grant that the body of an emotion is a system of relations among a group of ideas and sensations, and by that very fact it becomes capable of ideal representation, and subject to its laws.

'In this counection attention may be called to a critical review, by the present writer, of Witasek's paper, 'Zur psychologischen Analyse der Einfuhlang,' in this issue of the REVIEw. 
The emotional theories of art have taken the emotional state out of the sphere of mere emotional reaction to content (the sphere of pleasure and pain) and placed it in the sphere of content itself. This is the meaning of the æsthetic theories of Einfuhlung and Scheingefühlen. The condition of representation to consciousness of any content is that it shall be segregated from the rest of consciousness by attention. When zsthetic theory, in its psychological analysis, shall have made clear the processes and the reasons for the processes which underlie the passage of the attention from the object to the complex of relationships which constitute the organic reaction to the object, the most difficult question of æsthetics will be solved. 